\title{
Measuring Park Usage in Malaysian Greens
}

\author{
Nurhayati Abdul Maleka, Manohar Mariapanº, Nik Ismail Azlan Ab Rahmanc \\ a Department of Landscape Architecture, Kulliyyah of Architecture and Environmental Design, International Islamic \\ University Malaysia (IIUM), Kuala Lumpur, 53100, Malaysia. \\ b Faculty of Forestry, University Putra Malaysia (UPM),Serdang,43300, Malaysia. \\ c Department of Landscape Architecture, Faculty of Architecture, Planning and Surveying, \\ Universiti Teknologi MARA (UiTM), Shah Alam, Selangor, 40450 Malaysia \\ amnurhayati@iium.edu.my
}

\begin{abstract}
This study validates the park usage scales for green open spaces in Malaysia. The measures on park usage were developed using three usage scales, which are activities, passive activity and active activity. Samples of 414 daily park users were analyzed, results showed good-fit indices on each construct confirming the theory behind each and every item used in the study. Despite several reductions on the items, the Confirmatory Factor Analysis(CFA) on park usage yield good internal consistencies making it suitable for its use in the research design focusing in measuring the usage of Malaysian park users.
\end{abstract}

Keywords: Park Usage; Green Open Spaces; Malaysian; Measurement; CFA.

eISSN 2398-4295 @ 2018. The Authors. Published for AMER ABRA cE-Bs by e-International Publishing House, Ltd., UK. This is an open-access article under the CC BY-NC-ND license (http://creativecommons.org/licenses/bync-nd/4.0/). Peer-review under responsibility of AMER (Association of Malaysian Environment-Behaviour Researchers), ABRA (Association of Behavioural Researchers on Asians) and cE-Bs (Centre for EnvironmentBehaviour Studies), Faculty of Architecture, Planning \& Surveying, Universiti Teknologi MARA, Malaysia.

DOI: http://dx.doi.org/10.21834/ajbes.v3i10.81 


\subsection{Introduction}

The lack of consistent association in assessing the park usage aspects within the area of residential neighbourhood might be caused by the difficulties in defining, measuring, and assessing the usage among park users' in neighbourhood parks. However, there are several recent studies that explore and measures green spaces in urban areas. The studies include the development of Urban Neighborhood Green Index (UNGI) as measurement on green spaces in urban areas, the study on quality and quantity public open space (POS), the study on the assessment of quality Neighbourhood Park criteria (QNPC) as well as a study that examines the guidelines and policies in Shah Alam, Malaysia (Gupta et al., 2012; Francis et al., 2012; Abdul Malek et al., 2012; Marzhuki et al., 2012). However, this study differs as it looks specifically in the research design stage, where a confirmatory factor analysis (CFA) method was adopted to validate the instrument used to measure variables associated with only the park usage indicators.

Green infrastructure is believed to offer more benefits; physically, emotionally and socially as well as to encourage urban communities to live healthily by going outdoor (Mansor et al., 2010). The main purpose of this study is to gain an increased understanding on the Malaysian park usage aspects of park users in neighbourhood green open spaces. Currently, there is no particular tool or assessment within the Malaysian housing and local authority level to measure the usage aspect of the neighbourhood green. It is therefore, important that this validation is well tested using the current and important theories as well as past studies.

\subsection{Literature Review \\ Park Activities and Usage}

Recently, the preferred uses of outdoor activities are swimming, relaxing, tennis, bicycling and basketball. The variation of activities chosen by users was most likely influenced by the age group. Young people with age ranging from 13 to 18 years old prefer active and waterrelated activities. On the other hand, adults (19 to 60 years old) and senior citizens (60 years old and above) have higher preferences in passive activities, which could be, referred to as 'relaxing' use, and perceptions of urban greenways (T.W. Zhang and Gobster, 1998; Lindsey, 1999).

The most common activities are walking, running/jogging, bicycling and skating as users were found to be frequently used the trails at least more than three times a week. Health and fitness were among reasons found to the use of greenway trails along with factors such as quality of maintenance and trail features. However, cleanliness and conflict of use seem to be the main problems here. Arnberger (2006) indicated that the peak time for recreation use was usually between late morning and late afternoon mainly during weekends with the presence of joggers, bicyclist, walkers and dog walkers. As well, distance to the resource does not extensively affect park use or perceived park use benefits according to ethnic groups.

Correspondingly, parks with extra features were more preferred to be used for physical activity as the park facilities such as wooded area and paved trails have the most powerful 
relationship with the park use. In contrast, size and distance to the park itself were not significant (Kaczynski, Potwarka, and Saelens, 2008). Location of greenway trails and accessibility as well as, equality of access, are the significant factor in perception of use among visitor. Even a 5 mile local trail, would be too far, especially, for older adult users (more than 55 years old). The design consideration of the trails too should be sensitively and responsive to meet various users' needs and expectation (Gobster, 1998; Shukur, Othman \&Nawawi, 2010; Kurniawati, 2012). Hence, the dependent and independent variables as well as the attributes were further expanded as shown in Table 1.1 below.

Table 1.1: The dependent variables, independent variables and attributes used in this study based on Use construct derived from the literature review findings

\begin{tabular}{|c|c|c|c|}
\hline $\begin{array}{l}\text { Dependent } \\
\text { Variables }\end{array}$ & $\begin{array}{l}\text { Independent } \\
\text { Variables }\end{array}$ & Attributes & \\
\hline & Active Activity & - Cycling & - Swimming \\
\hline & & - Skating & - Pets walking \\
\hline & & - Walking & $\begin{array}{l}\text { - Basketball } \\
\text { Tennis }\end{array}$ \\
\hline & & - Jogging & \\
\hline & Passive Activity & $\begin{array}{l}\text { - Relaxing/Fishing/Playing Board } \\
\text { Games }\end{array}$ & - Meet Friends \\
\hline & & - Celebrations (Birthdays/parties) & $\begin{array}{l}\text { - Spend time in open } \\
\text { air }\end{array}$ \\
\hline \multirow[t]{5}{*}{ Usage } & & - Picnic \& Barbecuing & $\begin{array}{l}\text { - Rest by water } \\
\text { \&green }\end{array}$ \\
\hline & Activities & - Wooded area & - Trail location \\
\hline & & - Smaller lot size area & $\begin{array}{l}\text { - Design } \\
\text { management }\end{array}$ \\
\hline & & - Accessibility & - Paved trails \\
\hline & & - Quality of ambience & \\
\hline
\end{tabular}

Consequently, all reviewed items on park usages in neighbourhood green open spaces from the literature in this paper were analyzed to assess the overall usage aspect. These new measures of usages under analysis include three constructs representing usage in a neighbourhood park are; activities (10 items); passive activity (3 items); and active activity (2 
items) as presented in Table 1.3.

\subsection{Methodology}

\section{Participants}

The total participants for the study were 414 park users daily, in two local neighbourhood parks in Malaysia. Two study areas were used, the first one is Taman LembahKiara, in Taman Tun Dr. Ismail, Kuala Lumpur and the second one is Taman RimbaRiang, in Kota Damansara, Petaling Jaya. Both parks were located in two different local authority jurisdictions but accessible in so many ways within a short distance of $10 \mathrm{~km}$ between each other. The two sites were selected because the similarity of both community characteristics which are mainly occupied by middle low to upper or high income group, neighbourhood housing areas that were heavily connected to a commercial area and that the neighbourhood developments is well connected to neighbourhood parks.

\section{Characteristics of Sample}

This section describes the socio demographic profiles of all four hundred and fourteen (414) respondents who took part in this study. The majority of the respondents or $64.3 \%(n=266)$ were those from Taman RimbaRiang, Kota Damansara and 35.7\% ( $n=148)$ were from Taman LembahKiara, Taman TunDr. Ismail. Table 1.2 shows the sample site of the respondents' survey.

Table1.2: SampleSize by Park

\begin{tabular}{lcc}
\hline Park & $\begin{array}{c}\text { Number of participant } \\
\text { respondents }\end{array}$ & $\%$ \\
\hline $\begin{array}{l}\text { Taman LembahKiara, Taman Tun Dr. } \\
\text { Ismail }\end{array}$ & 148 & 35.7 \\
Taman RimbaRiang, Kota Damansara & 266 & 64.3 \\
\hline
\end{tabular}

Note. Total sample size for the study $=414$

\section{Development of the Instrument and Procedures}

The research instrument was developed based on the literature analysis as well as the items tested on usage attributes. Then, integrating various useable items from usagestudies further developed it. Every measurement were structured using 5-level Likert scale which are 1: Strongly disagree; 2: Disagree; 3: Neutral; 4: Agree and 5: Strongly Agree.

\section{Confirmatory Factor Analysis (CFA)}

An explicit goal of CFA according to Byrne (2001) is where there is some knowledge of the theory or empirical research where the relationship between the observed measures and the primary factors is known and that it is tested statistically. Thus, the fundamental method of 
CFA estimates only unexamined associations among factors and not the direct underlying effects (Kline, 2005). Critical ratio (CR) is used to test the significance of each path coefficient. According to Bryne (2001), CR or estimated path coefficient is significant when it is more than 1.96 at .05 levels.

\subsection{Results and Discussion}

\section{Socio-demographic Characteristics}

The socio-demographic characteristics shows more female park users were found in Taman RimbaRiang in Kota Damansara. About 59.4\% ( $n=158)$ females and $40.6 \%(n=108)$ males visitors were interviewed using the park at their selected time frame. Whereas for Taman Lembah Kiara, the gender distribution seems to be average among both gender with $50.7 \%$ $(n=75)$ females and $49.3 \%(n=73)$ males visitors respectively.In term of age, more than a quarter of the respondents or $30.4 \%$ were between the ages of $20-25$ years old $(n=126)$ who were identified to have visited the park more than any other age group categories. Similarly, the second largest age group categories or $17.1 \%(n=71)$ are those from the range of $26-$ 30 years old, followed by $16.7 \%(n=69)$ aged between $0-19$ years old. This shows that the demographics of the park users were relatively young in age. Only $4.3 \%(n=18)$ were the older groups of park visitors, age between 46 - 50 years of age while, about $8.5 \%(n=35)$ were the oldest group of 51 years of age and above. For the whole, the female park users of all age group categories seem to be dominating as park users in this study.

\section{Frequency of visitations}

The basic demographic questions in this study also asked about the frequency of visitations to both parks. About $30.3 \%(n=116)$ of the park users visited both of the parks on every weekend. Most of the users or about $30 \%(n=115)$ also happened to be visiting the park every 1 to 3 times in a month. Only $1.8 \%$ visited Taman LembahKiara every day while $4.7 \%$ visited Taman RimbaRiang on a daily basis. It was also surprising that about $8.4 \%(n=32)$ had never visited both of the park before, and that, it was their first time to the parks.

\section{Length of stay}

Nearly half or $43.2 \%(n=168)$ of the park users were identified to be using the park within one-hour time. About $29.6 \%(n=115)$ were identified to be from Taman RimbaRiang while about $13.6 \%(n=53)$ were those from Taman LembahKiara. In the other hand, the second largest groups were identified as those who visited the park between $2-4$ hours at every visit. This was about $17.2 \%(n=67)$ in Taman LembahKiara and $21.9 \%(n=85)$ in Taman RimbaRiang. Similarly, only $15.4 \%(n=60)$ visited the park lesser than one hour and only $0.8 \%$ visited the park full day. This could be indicated that outdoor green open spaces still seem to be important recreational venues among neighbourhood park users in this study. 


\section{Distance to Neighbourhood Park}

The length of stay to both of the parks does not seem to be related to the distance of the neighbourhood park from the park user's home. This is because, most of the respondents were identified to be staying more than $5 \mathrm{~km}$ from the park $(n=97 ; 24.9 \%)$ and yet, they still visit the park at least on the weekend. Most of the neighbourhood park visitors mentioned that the distance between their home and the park is about $1 \mathrm{~km}-2 \mathrm{~km}(\mathrm{n}=23 ; 5.9 \%)$ for Taman LembahKiara and $(n=74 ; 18.9 \%)$ Taman RimbaRiang. Only about $n=49(12.6 \%)$ stayed at a distance of $4 \mathrm{~km}-5 \mathrm{~km}$ from the neighbourhood park. This shows that distance do not play an important role for park visitations among park users.

\section{Usage in Neighbourhood Park}

Table 1.3 indicates the park usage in Neighbourhood Park; about $65 \%$ agreed that a neighbourhood park should have Food and Beverage (F\&B) kiosk while 54\% disagree that they will only visit the park when there is a special event going on. On the reverse statements given in the questionnaire, about $72 \%$ enjoyed the sound of water in the park, $67.2 \%$ prefer many trees in the park; $59.4 \%$ do not like to fish in neighbourhood park; $63.3 \%$ prefer larger parks; $43.3 \%$ only come to the park to meet friends. About $58 \%$ disagreed when asked if they have often celebrated birthday parties or even BBQ with friends and family in the park. In the other hand, only $10.6 \%$ walk their pets to the park; $20.5 \%$ walk in the park every day; only $23.4 \%$ jog in the park every day, which indicated that Malaysian park users do not normally recreate actively in the outdoors. The responses whether they usually relax alone by the pond or sit on the grass does not give any strong indication about their usage in the park as the results turn out to be about the same throughout the range.

Table 1.3: Distributions of Park Users' Usage in Neighbourhood Parks

\begin{tabular}{lccc}
\hline \multirow{2}{*}{ Usage Items } & \multicolumn{3}{c}{ Agreement Level $^{1}$} \\
\cline { 2 - 4 } & Disagree & Neutral & Agree \\
\hline I will only visit the park if there is some special event going on & 54.1 & 25.1 & 20.8 \\
I do not like the sound of water & 72.2 & 14.5 & 13.2 \\
I do not like this park as it have too many trees & 67.2 & 19.1 & 13.7 \\
I walk my pets to this park ever yday & 71.0 & 18.4 & 10.6 \\
I enjoy skating with my friends here & 57.7 & 24.6 & 17.6 \\
I often celebrate birthday parties or have BBQ with friends and family in & 57.9 & 23.7 & 18.4 \\
the park & 38.4 & 25.8 & 35.8 \\
I usually relax alone resting by the pond or sit on the grass & 43.2 & 25.1 & 31.6 \\
I only come here to accompany my children to the playground & 59.4 & 22.0 & 18.6 \\
I like to fish here & 63.3 & 21.0 & 15.7 \\
I prefer smaller parks & 43.3 & 22.7 & 34.1
\end{tabular}




\begin{tabular}{llll} 
Watching people is the only thing I do here & 45.2 & 23.7 & 31.2 \\
I often spend time in the wooded/forest area of this park only & 35.3 & 30.9 & 33.8 \\
I think some kind of F\&B kiosk is an absolute requirement for this park & 14.8 & 20.8 & 64.5 \\
I walk in this park every day & 48.8 & 30.7 & 20.5 \\
I jog here every day & 48.1 & 28.5 & 23.4 \\
\hline
\end{tabular}

Note: All entries are percentage; $n=414$.

${ }^{1}$ Agreement level are based on Disagree $=$ Strongly Disagree + Disagree; Neutral $=$ Neutral; Agree = Strongly Agree + Agree.

\section{CFA on Use Model (U)}

A confirmatory factor model was also tested on the three level of usage scales, namely: a) Activities; (b) Passive Activity and (c) Active Activity. All factors are inter-correlated, indicated by two-headed arrows. There is a total of 16 observed usage variables. They represent various usage items selected in the green open spaces literature. The observed variables load on the factors in the following pattern: USE_1 until USE_10 load on Factor 1; USE_11 until USE_13 load on Factor 2; and finally USE_14 until USE_16 load on Factor 3. All USE factors were correlated and inaccuracy of measurement associated with each observed variables (err01 - err16) are uncorrelated.

The model was also considered being a fit model with standardized estimates of RMSEA value (0.064), CFI (0.942), GFI (0.935) with $p=.000$. Table 1.3specified that all factor loadings of USE indicators were significant at 0.005 levels. Based from the confirmatory model, only USE_14 under usage construct was deleted because the factor loading was below 0.40 . Among other important additional measurement were NFI (0.912), IFI (0.942), AGFI (0.902) and TLI (0.923). This has remained to only 15 items in USE confirmatory factor analysis model.

\subsection{Conclusion}

The results from this study supported and therefore, indicated that there were significant correlations between the qualities of green open spaces with the use and between the usages with the satisfaction aspect of park users. This also can be concluded that there is a direct relationship between use and quality green open spaces. Hence indicating that park usage is obviously an important aspect to consider in relation to assessment and development of quality neighbourhood parks. Overall in Malaysia, it could be generalized that people often come to neighbourhood parks, not only to play games such as tennis, badminton and skating, but they also come to the park to accompany their children to the playground or even just to leisurely meet with friends nor walk or jog in the park every day.

Generally, Malaysian park users' do not prefer smaller parks, they do not like to fish in the park or walk their pets to the park. At the same time, the positioning of trails and pavements was regarded to be fairly important, and finally majority of the park users' agrees that the park is useable when the areas within the park are properly designed. Hence, this could answer to the research question that the pattern of use among Malaysian park users' 
could be similar to those park users in other Neighbourhood Parks in any other part of the world.

In light of these matters, this study in the other hand indicated that recreation use among Malaysian park users in terms of usage timing is most likely to be at its highest between late morning and late afternoon especially during weekends with the occurrence of many bicyclist, jogger, walker and dog walker. Most of the Malaysian park users also only use the Neighbourhood Park within one hour while only minority visited the park full day. This could indicate that Malaysian warm and highly humid climate could most probably defer park users from using it for longer hours during the day. In the other hand, park distance does seem to be related to the length of stay among Malaysia park users. This is because, based from the result, even those who were identified to be living more than $5 \mathrm{~km}$ away from the park, and visited the Neighbourhood Park at least on every weekend.

As the final say, this study has confirmed several usageaspect, which contributed from community participation to better usage among residents in the neighbourhood. This study also confirms that the neighbourhood park development does help create a more meaningful experience to park users. Hence, designers should strive to create quality neighbourhood parks not only to boost the value of the surrounding neighbourhood but to also give more overall benefit and experience to the day-to-day users.

\section{References}

Abdul Malek, N., Mariapan, M., \& Shariff, M. K. M. (2012). The Making of a Quality Neighborhood Park: A Path Model Approach. Procedia-Social and Behavioral Sciences, 49, 202-214.

Arnberger, A. (2006). Recreation use of urban forest: An inter-area comparison. Urban Forestry \& Urban Greening, 4, 135-144.

Byrne, B. M. (2001). Structural Equation Modeling with AMOS: Basic Concepts, Applications, and Programming. New York: Taylor \& Francis Group \& Lawrence Erlbaum Associates, Publishers.

Francis, J., Lisa J.Wood, Mathew Knuiman, Billie Giles-Corti. (2012). Quality or quantity? Exploring the relationship between Public Open Space attributes and mental health in Perth, Western Australia.Social Science \& Medicine, 74, 1570-1577.

Gobster, P. H. (1998). Urban parks as green walls or green magnets? Interracial relations in neighbourhood boundary parks.Landscape and Urban Planning(41), 43-55.

Gupta, K., Kumar, P., S.K.Pathan, \&K.P.Sharma.(2012). Urban Neighborhood Green Index - A measure of green spaces in urban areas.Landscape and Urban Planning, 105, 325-335.

Kaczynski A.T., Potwarka, L.R. \&Saelens, B.E., (2008), Association of park size, distance, and features with physical activity in neighbourhoodparks.American Journal of Public Health, 98, 1451-6.

Kline, R. B. (2005). Principles and practice of Structural Equation Modeling (second ed.). New York: The Guilford Press. 
Abdul Malek, N., et.al. / Asian Journal of Behavioural Studies (AjBeS), 3(10) Mar / Apr 2018 (p.65-73)

Lindsey, G. (1999). Use of urban greenways: insights from Indianapolis. Landscape and Urban Planning, 45 145157.

Marzhuki, M. A., Karim, H. A., \&Latfi, M. F. (2012).Evaluating the Shah Alam City Council Policy and Guidelines on the Hierarchy of Neighborhood Open Space.Procedia-Social and Behavioral Sciences, 36, 456-465.

T.W. Zhang and P.H. Gobster, (1998) Leisure Preferences and Open Space Needs in an Urban Chinese-American Community, Journal of architectural and planning research, 15(4), pp. 338-355. 